\title{
Visualising Climate and Climate Change A Longue Durée Perspective
}

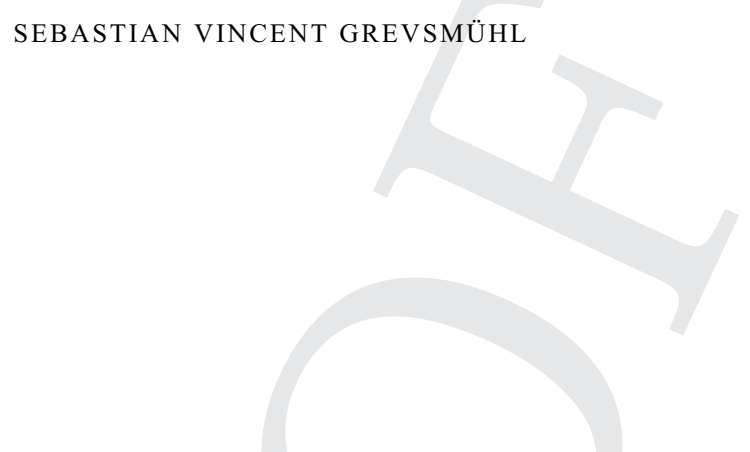

\subsection{Introduction}

This chapter explores the challenging terrain of images and scientific visualisations as a way of investigating and understanding climate and climate change within the context of society and culture. I retain the notions of images and visualisations here, as opposed to representation, in order to avoid the numerous metaphysical connotations the action of 're-presenting' may imply (Rheinberger 2001). Visualisation in the context of climate change is thus understood as a means of knowledge construction, and it necessarily implies imagination, political sensibilities, as well as material actions. My focus here will be on spatial visualisations of climate in the form of maps and in particular the history of climate classifications. The study draws mainly on a systematic investigation of several important scientific map collections, complemented by careful readings of several influential scientific treaties on meteorology and climate, as well as a critical survey of the available historical literature on climate and its cultural understandings. ${ }^{1}$ Some of the questions I would like to address here are: What would a longue durée history of climate visualisations look like? What can graphs and maps tell us about a changing climate and its history? And more importantly, what can we learn from such a longue durée visual perspective, in particular within the contemporary context of anthropogenic climate change?

I argue that adopting a longue durée perspective can be fruitful because current debates on climate change resonate astonishingly well with many early questions

\footnotetext{
${ }^{1}$ Several important map collections have been partially digitised, the most important being the private Rumsey map collection (www.davidrumsey.com), with over 83,000 items available online (January 2018). A very useful resource on especially nineteenth-century geographical atlases can be found at www.altassen.info. Moreover, some thematic map exhibitions, in particular 'First X, Then Y, now Z' by John Delaney at Princeton University Library, were also very helpful.
} 
philosophers and cartographers wished to address when they first mapped out 'climates'. Indeed, some of the major motivations were strikingly contemporary in nature - for instance, defining the role geographical regions play in harbouring favourable conditions for life, exploring the various ways in which climate may relate to population and migration, and finally reflecting on the kinds of world we can, or cannot, live in. To put it in other words: since the introduction of the notion of 'climate' and related vocabulary, fundamental explorations of our being and living in this world are at the very heart of climatic thinking.

As I will show below, approaching this set of questions from the visual realm can prove fruitful for several reasons. Visualisations, as the word indicates, fulfil an important role in rendering the invisible visible, and this is particularly true for the context of climate change where the vast majority of geophysical structures, processes and phenomena would otherwise stay out of reach of investigation. Climate visualisations form an important part of this interrogation. Maps in particular played (and still play) a leading role in shaping our understanding of the Earth's climates, regrouping important cultural resources of diverse nature, fuelled (in function of varying historical contexts) by reasoning of biblical, cosmological, geographical or geophysical nature. In the past, climate knowledge was, in other words, never stable, and the ways in which we think about climate has changed considerably, invoking at times highly disparate concerns related to medical, agricultural, geographical, economic and even racial questionings (Fleming and Jankovic 2011). 'Climate' should thus be read here in a broad sense, because of its unstable and shifting meaning over time, evolving constantly according to varying social and cultural contexts.

Indeed, as Heymann rightly points out in his genealogy of climate ideas, 'different understandings of climate were instrumental for the shaping of scientific interests and directions of research and the formation of scientific and public discourses about climate' (Heymann 2010:581). This should, however, not obscure the fact that climate, and in particular its changes, was hard to seize by science and, more importantly, that the view from science tells us of course only one small part of this story. As historians Locher and Fressoz have shown, François Arago, for instance, enlisted as France's climate expert during the first half of the nineteenth century, had to admit that in the absence of long-term meteorological records and in regard of the huge uncertainties attached to the climate question, a serious scientific investigation was an impossible task (Locher and Fressoz 2012). This did not mean that learnt discourse did not have important things to say about climate and its changes. Indeed, in order to adopt a longue durée perspective on climate and its changes, we rather have to engage in now-defunct understandings of 'climate theory where technique, political form, environment, and bodies all overlapped' (Locher and Fressoz 2012:581). 
Some of the major shifts in past understandings of climate and its changes are captured by the rich iconography mobilised to visualise climate ideas and theories, others did not find entry into the visual realm and others again reveal historical transitions which sit squarely with received historical conceptions of climate change. So before considering the realm of contemporary climate change visualisations addressed at the end of this chapter, it is worthwhile asking which role images played in the forming of our understandings of climate in a longue durée perspective. This chapter thus speaks to a growing interest in understanding in more detail what 'climate' and 'climate change' mean culturally, revealing in particular how and why the dominant physical and statistical history of climate is closely interwoven with its cultural history (see also Hulme 2015).

\subsection{Shifting Meanings in Climate Visualisations}

Climatic theories and ideas were from the very beginning closely associated with images, in particular maps and diagrams. Amongst the earliest 'climate' maps historians have at their disposal today, one may count what contemporary map classification systems identify as medieval zonal maps. ${ }^{2}$ These maps are all based upon or were inspired by Macrobius' Commentary on the Dream of Scipio from the early fifth century. Images were central to the Commentary because the text gives very precise instructions on how to draw four diagrams, and in particular a zonal diagram, showing the division of the Earth into five 'bands' or 'belts' made up of the 'frigid', 'temperate' and 'torrid' zones, with only the two temperate zones considered habitable, and only the northern one for sure. Many of these medieval zonal diagrams have a strikingly 'contemporary' look, not only because most of the hand-painted copies which were made throughout the Middle Ages mobilise a very familiar colour coding still in use today - with red systematically attributed to the torrid zone and blue often reserved to the frigid zones, as may be observed in Figure 3.1 showing a French example from around 1150 - but also because zonal division remains until today deeply enshrined in Western geographical imagination.

The importance of images is very clear here because all diagrams were explicitly conceived as pedagogical tools, allowing, according to Macrobius, to apprehend more easily the idea of zones (Hiatt 2007). The initial concept was introduced by Pythagoras, Parmenides and Aristotle not on observational but purely astronomical and mathematical grounds (Altmann and Schramm 2005). The idea was to express geographical differences in sunshine due to the inclination of the Sun relative to the Earth's surface. Thus, early twentieth-century historical commentators, such as climatologist Robert Ward, referred to the three types of zones as 'zones of solar

2 Sometimes they are also referred to as 'hemispheric' maps because they always show only one hemisphere. 


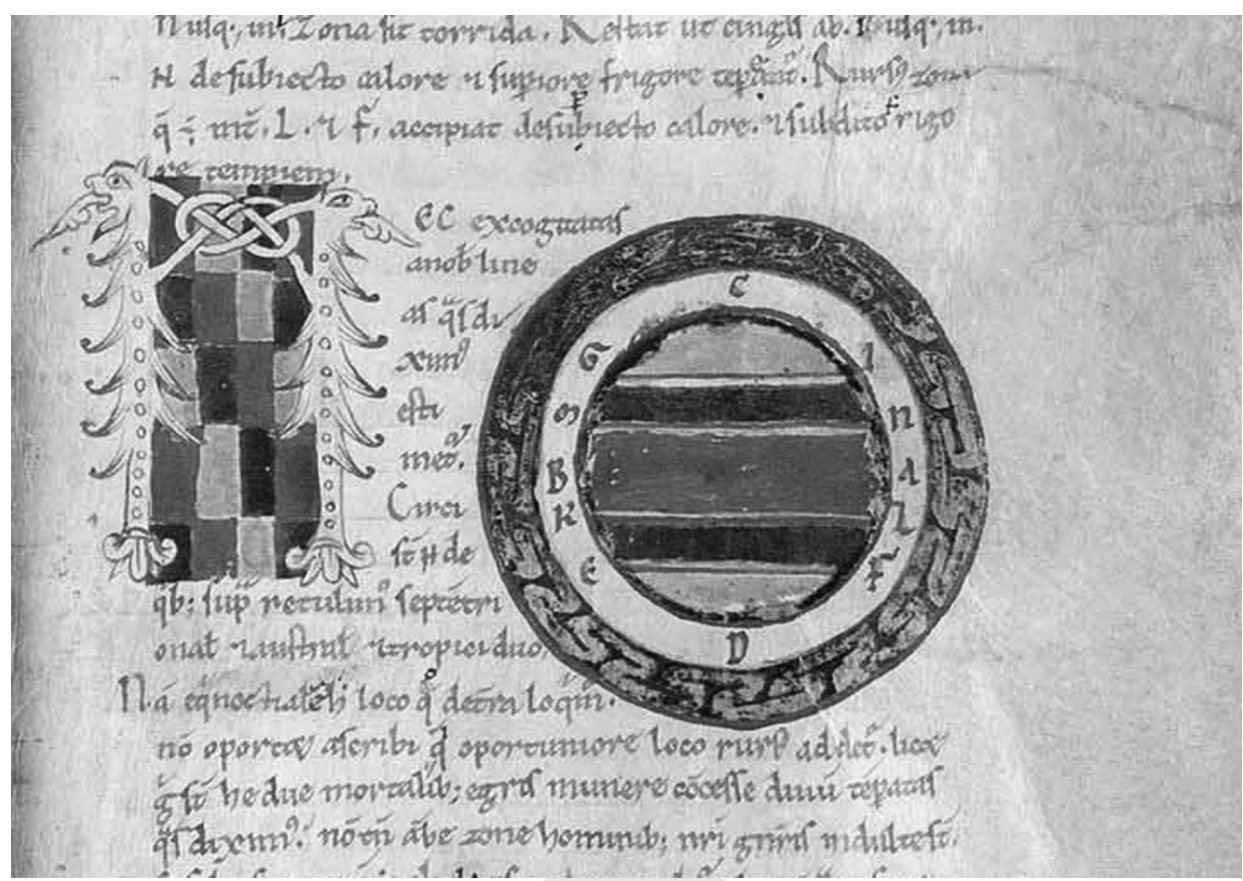

Figure 3.1 The five zones of the Earth according to Macrobius' commentary on Cicero's Somnium Scipionis, c. 1150 (Source: Wikimedia Commons)

climate' (Ward 1905:386; see also Ward 1908), remobilising a notion Humboldt had already popularised in 1813 in order to differentiate what he calls 'solar climate' and 'real climate' (von Humboldt 1813:471). The zonal diagrams were often accompanied by what is known as Macrobius' world map which included (in its standard version in copies of the text produced by scribes from the tenth century onwards) five zones, a schematic outline of the relationship of ocean to land in the northern hemisphere, an equatorial ocean and symbols indicating the direction of ocean flows moving from the equator to the poles (Hiatt 2007).

Curiously, however, the actual term 'climate' was not used for the zonal descriptions because it was reserved for a long time for another tradition that I also would like to briefly discuss here. Although at first sight conceptually close - because visualised together on maps at many occasions in particular during the eighteenth century - the five zones depicted in zonal diagrams are not to be confused with the ancient Greek geographical concept of klima by which initially only parts of the northern hemisphere were first divided into seven, later nine parallel, horizontal bands, the klimata. Often named after the places through which they passed (Meroe, Syene, Alexandria and so on), these early klimata were distinguished from one another by the length of their solstitial day, and at first they were all 
located within a single zone, the temperate zone. This coincided at the same time with the oikoumene, believed to be the only inhabited part of the Earth (Corneille 1708; see also Honigmann 1929; Hiatt 2007).

For the Western context, it is important to note that this tradition is historically closely linked to Ptolemaic ideas. Ptolemy's reintroduction during the fifteenth century in the Western world was made possible through Islamic scholarship where ancient Greek natural philosophy was intensely conserved, studied and translated, and unsurprisingly, one of its most famous and influential examples, the Al-Idrisi map commissioned in the twelfth century by King Robert II, Norman ruler of Sicily, included seven climates in Ptolemaic tradition (see map reproduced in Cosgrove 2007:87; see also Honigmann 1929). In Europe, this cartographic tradition of 'climates' reaches back, for instance, to the 1480 atlas Geographia from Francesco Berlinghieri that contains a colourful world map depicting seven climates (Berlinghieri 1480), and this tradition was continued by many cartographers throughout the sixteenth and seventeenth centuries (e.g. Fries 1541; Ruscelli 1561). Other typical visual examples can be found in world maps redrawn after ancient Greek knowledge, for instance, the commentary of Strabo published in 1731 by Christoph Cellarius, showing a map of the northern hemisphere with seven parallel climates, numbered 1 through 7, running through Meroe, Syene and so forth, each line separated by half an hour difference in length of day (Cellarius 1731). As a distinct, separate cartographic tradition, this geographic climate category remained astonishingly stable well into the latter half of the eighteenth century. All of these visual examples show well that at its origin, the word 'climate' was not at all defined in terms of temperature or meteorological conditions but rather associated with the idea that a change of location, where the longest day is, say, half an hour or an hour longer than at the starting point, represents a change in climate.

\subsection{The Slow Erosion of Fixed Divisions and Boundaries}

The fifteenth and sixteenth centuries' voyages and discoveries, however, progressively made these divisions and boundaries more fluid, particularly in regard to the question of the extension of the habitable world in certain zones, but also in regard of the number of climates to be included. Indeed, the 'torrid zone' was not only inhabited in many places but it also could be traversed. Moreover, the voyages to the New World proved that the new lands had meteorological conditions that were not simple extrapolations of the known European ones. Historian Anthony Grafton, for instance, mentions the telling story of Jesuit scholar and traveller José de Acosta whose 1580 treatise on the New World describes his incursion into the 'torrid zone' as a rather chilling experience: he and his fellow travellers were not dying of heat - they were 
actually feeling cold (cited in Martin 2006:3). Also the seven traditional climates were successively extended, in particular because of early 'polar' exploration reaching far into the 'frigid zone'.

As a consequence of direct observation and the rapid expansion of the oikoumene, ancient Greek knowledge started to be questioned, at least in part, even though Aristotelian natural philosophy and climatic theories forged by Hippocrates proved astonishingly flexible and adaptable in the long run (Martin 2006). To be sure, the idea of the inhabitability of the 'torrid zone' was firmly rejected by most scholars from the sixteenth century onwards. However, causal climatology and climatic determinism remained well into the eighteenth-century influential climate doctrines, especially in medical climatology. As a philosophical doctrine, climatic determinism was frequently mobilised to explain differences in cultures and societies (Heymann 2010). Indeed, as Jim Fleming and other historians have shown, the second half of the eighteenth century was dominated by climatic concepts introduced by Abbé Du Bos, Montesquieu and Hume which forged the idea that cultures are determined or at least fundamentally shaped by climate and that, in turn, the collective actions of society shape the climate itself (Fleming 1998).

What counts here is that in world maps, zonal distribution (mostly five zones) and the 'modern' division of the globe into twenty-four or thirty 'climates' persisted side by side throughout the seventeenth and eighteenth centuries, yet without really interacting with each other (Mauelshagen 2016). This historical evolution is neatly summarised not in a map but in a hierarchical diagram, published by cartographer Nicolas Sanson's son Guillaume (Sanson and Sanson 1697). The diagram describes in detail which elements should be included in terrestrial globes and world maps, distinguishing in particular the two dominant, separate types of classification: 'zones' and 'climates'. According to Sanson, the 'zones' are made up of the classic three types ('one torrid, two temperate and two cold or frozen') as discussed above. 'Climates', on the other hand, underwent a historical transformation. Whereas the ancient Greek identified first seven, later nine 'climates' (running through well-known places and landmarks such as Meroe and Syene as discussed above), the 'moderns' defined thirty different 'climates', namely twenty-four for every half hour between the equator and the polar circle, and six for each month between the polar circle and the pole. Typical world maps would thus include both zonal and climate distribution in function of solstitial days. ${ }^{3}$

\footnotetext{
3 The Rumsey map collection contains numerous examples illustrating this fact, such as the French 'Mappemonde géosphérique ou nouvelle carte idéale du globe terrestre' of Lattré from 1760, or the Italian 'Il mappamondo o sia descizione generale del globo' of Zatta/Pitteri from 1774. See: www.davidrumsey.com/ (accessed 5 December 2017).
} 
However, not only the voyages to the New World made abundantly clear that neither day length nor latitude was a reliable or even useful indicator for meteorological conditions to be encountered when travelling around the globe. It was the rapidly growing popularity of weather instruments, especially during the eighteenth century, which brought about a quantitative approach to weather recording, even though this was a gradual process that once again does not easily fit into the idealised accounts of the Scientific Revolution. As historians Jankovic and Golinski have shown for the British case, meteorological observations were guided well into the eighteenth century by classical Aristotelian conceptions and remained often qualitative and descriptive (Jankovic 2000; Golinski 2007). Yet with such important inventions as gauges, barometers, manometers, thermometers, hygrometers and even machines designed to measure the speed of winds, the material basis was laid for empirical weather research which was at the origin of physical climatology, and this shift became increasingly clear from 1750 onwards.

The slow emergence of a modern understanding of climate is precisely captured by the famous Encyclopédie of Diderot and d'Alembert. The third volume from 1753 contains two 'climate' entries, a geographical and a medical one. After a classic explanation of half-hour and monthly climates, the first geographical entry written by d'Alembert also states: 'One should not be misled in thinking that the temperature is exactly the same in countries located in the same climate: because an infinity of circumstances, such as the winds, the volcanoes, the proximity to the sea, the location of the mountains, become more complex under the sun's action, and often render the temperature very different in places situated at the same parallel' (Diderot and d'Alembert 1753:533, own translation). The second, a medical entry written by physician and chemist Gabriel François Venel, is also very explicit, placing temperature at the heart of the climate definition: 'Physicians consider climates only as a function of temperature or degree of heat . . . climate, in this sense, is even exactly synonymous to temperature' (Diderot and d'Alembert 1753:534, own translation).

D'Alembert's and Venel's climate definitions thus stand paradigmatically for the slow introduction of a complex, physical understanding of climate, driven by the instrumental revolution, a change that took place gradually from the second half of the eighteenth century onwards. Heymann notes that this is also the period when a disciplined, non-personal engagement in observation started to become a dominant trait of systematic weather observations, even though still at a very reduced level (Heymann 2010). The climate notion thus gradually shifted to a physical understanding, introducing an important complexification, guided by causal reasoning and a new, dynamic interpretation of climate (Mauelshagen 2016). Once hegemonic from the mid-nineteenth century onwards, with the installation of the first monitoring networks and the establishment of meteorological 
societies, the empirical approach to weather research radically changed inherited conceptions of climate, an aspect to which I will turn in the next section (Locher 2008).

For this early period, it is important to note that zonal and climate maps provide some important insights when considering a longue durée perspective on climate and climatic thinking. First, zonal maps make very clear that the supposed fundamental 'break' or 'rupture' between traditional natural philosophy and new knowledge that emerged with the so-called Scientific Revolution was by no means an abrupt one. Many ancient beliefs persisted well into the eighteenth century, and others regained importance at times, such as causal climatology in the Hippocratic tradition, which experienced many revivals in the form of medical climatology as a framework for explaining differences in human culture, or as a hygienist doctrine during the nineteenth century supporting explanations of racial superiority (Heymann 2010; Locher and Fressoz 2012). The visual approach reveals that zonal distribution persisted as a classification system for centuries, mainly because it could easily be adapted and integrated into different theoretical and moral frameworks. Well into the twentieth century it served as a visual guide in teaching the concept of climate zones, often accompanied, as Livingstone has shown, by moral considerations. ${ }^{4}$ Moreover, this means that in this early period there is a dominant 'visual style' attached to the idea of climate that proved particularly robust throughout history, even though the meanings of 'climate' shifted of course substantially over time.

This visual continuity should, however, not obscure the fact that the word 'climate' was for a long time attached to a completely separate geographical cartographic tradition that is often completely overlooked, even though it had important repercussions for the history of climatology. Within cartography, both knowledge traditions started to merge during the middle of the eighteenth century, and as I will argue now, this merging led to a new climate classification at the beginning of the nineteenth century.

\subsection{Visual Contributions to a Quantitative Understanding of Climate}

Classical zonal distribution would not stay immutable throughout history. Indeed, the instrumental revolution brought about a new kind of 'zonality', based not on latitude but on temperature. And here again, the visual realm was fundamental in forging new ideas about climate, although it took relatively long to translate the growing number of

\footnotetext{
${ }^{4}$ Many geography textbooks continue well into the twentieth century to use zonal maps as pedagogical tools for teaching global climate distribution. For instance, in the 1907 edition of Matthew Fontaine Maury's classic textbook New Elements of Geography, one still finds on page 17 the idea of distinct zones defined according to the ancient Greek tradition. Well into the twentieth century, scientific accounts of atmospheric conditions are supplemented by moralistic pronouncements (Livingstone 2002).
} 


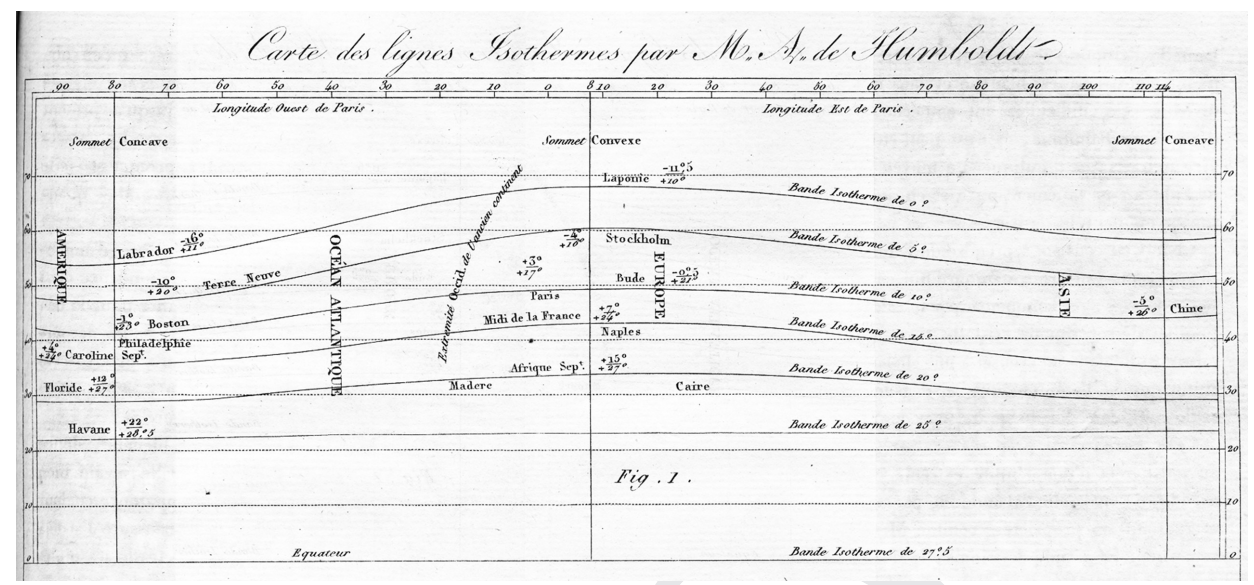

Figure 3.2 Isoline map as introduced by Alexander von Humboldt in 1817 showing mean temperature on a global scale (Source: Princeton Library Historic Maps Collection)

meteorological records into climate maps. One historical figure, as probably no other, is closely associated to this historical development: German naturalist and explorer Alexander von Humboldt. At the beginning of the nineteenth century, Humboldt laid important foundations for the nascent scientific discipline of climatology by popularising innovative visualisation techniques. One of the most famous visual tools he introduced to climatology can be found in a now well-known map showing so-called isothermal lines published in 1817 (Figure 3.2). This early climate map may be counted amongst the most influential examples of thematic mapping, even though its simplistic appearance does not render it immediately recognisable as a map. Humboldt's 'Carte des lignes isothermes' shows seven isolines (also known as contour lines), each connecting values of a selected average temperature, hence the notion 'isothermal line' coined by Humboldt. Here, the power of images becomes clearer than ever: the figure reveals a spatial phenomenon that if not mapped would not have any existence at all. Indeed, it is the masterful introduction of what I have called elsewhere a 'global imaginary' (Grevsmühl 2014), the visual creation of a geophysical phenomenon at a very important scale that nobody could or would ever see.

Moreover, in tracing the spatial distribution of average temperature, Humboldt took the crucial step from mere data collection (realised beforehand exclusively in the form of tables) to data analysis, resulting in careful scrutiny of the form of visual distribution, the numerous relationships between different phenomena and, most importantly, their underlying laws. The 'map of isothermal lines' is thus precisely what Regnauld calls a 'visual model', reaching well beyond mere illustration because it expresses a completely new theoretical concept (Regnauld 2016). 
This fundamental shift, which marks in this sense (at least in the visual realm) the birth of modern climatology, is well known today, yet it remains too important a shift to be ignored. Several features of Humboldt's map are worth being noted here. First, reduced to an absolute minimum of information, the cartographic content is merely suggested here. The outlines of the continents are not shown but the graticule and the geographical inscriptions (as, for instance, 'America', 'Europe' and 'Asia') indicate that we are looking at a map showing large parts of the northern hemisphere, centred on the meridian of Paris. Yet the true radical novelty of this map is the introduction of a new type of 'zonality' based on seven isolines of average temperature and differentiated by mostly $5^{\circ} \mathrm{C}$ steps. The map shows at first in the North the $0^{\circ} \mathrm{C}$ isotherm passing through Lapland, moving in $5^{\circ}$ $\mathrm{C}$ steps all the way down to the sixth isotherm of $25^{\circ} \mathrm{C}$ running through Havana, and finally the equator, which coincides with the isotherm of $27.5^{\circ} \mathrm{C}$. Henceforth, climate was defined as a statistical representation of weather based on carefully selected field observations. ${ }^{5}$

Although there is an obvious visual resemblance with the geographical climate tradition - and as a visual style, isotherms helped in fact connect the visual tradition of ancient zonal theory to the geographical tradition - Humboldt himself sought inspiration not in Eratosthenes nor Parmenides but in a novel data visualisation technique of another global imaginary, first introduced (when considering a global scale) by Edmond Halley in geomagnetism in around 1700, showing magnetic declination at a truly global scale and based on actual measurements. Halley was already aware of the immense possibilities his innovative visualisation techniques may could offer (in particular because he also drafted one of the first known meteorological charts), claiming that with his novel maps many natural phenomena 'may be better understood, than by any verbal description whatsoever' (Halley 1686:163; see also Wilford 1981).

Humboldt agreed of course with this view as he was deeply convinced of the usefulness of visualisation techniques for global data analysis, stating that ' $[\mathrm{t}] \mathrm{he}$ use of the graphic method will help clarify phenomena which are of the highest interest for agriculture and for the social state of the inhabitants. If instead of geographical maps, we only possessed tables covering latitude, longitude and altitude, a great number of curious relationships, offered by the configuration and unequal surface qualities of the continents, would have stayed for ever lost' (von Humboldt 1813:510-11). Citing Halley's preliminary work on isolines, Humboldt further wrote: 'I traced on a map isothermal lines analogous to lines of magnetic

\footnotetext{
5 Although field observations are crucial to the map, isolines create the illusion of continuous measurement, effectively hiding the number of actual measurements used in the construction of the map (see Grevsmühl 2014). For instance, despite its global appearance, Humboldt retained only fifty-eight places to construct his isothermal map (see Schneider 2016).
} 
inclination and declination' (von Humboldt 1813:488), finding that on many occasions 'they are neither parallel to the equator, nor parallel to each other' (von Humboldt 1813:511).

Humboldt's groundbreaking contribution to the nascent field of climatology thus consisted mainly in successfully disconnecting climate from the rigid parallels, separating temperature from latitude with the help of a powerful visualisation tool, the isoline, that he helped popularise during the first half of the nineteenth century. Henceforth, neither latitude nor day length would be deemed appropriate criteria for climate description. Temperature, and in particular average temperature, would be retained as one of the most important guiding criteria. This fundamental choice is still at the basis of our current definition of climate, which, according to the third Intergovernmental Panel on Climate Change (IPCC) report, is referred to in common parlance as 'the average weather' and involves in scientific terms 'the statistical description in terms of the mean and variability of relevant quantities [temperature, precipitation, etc.] over a period of time ranging from months to thousands or millions of years' (IPCC 2001).

\subsection{Humboldt's Lasting Legacy}

The first to adopt Humboldt's novel visualisation technique in America was a Christian educator and school teacher, William Channing Woodbridge. His map titles 'Isothermal Chart, or View of Climates \& Production Drawn from the accounts of Humboldt \& others' from 1823 (Figure 3.3) shows for the first time the relationship of mean annual temperatures to crop growth and world climates. The carefully hand-coloured map visually merges the well-known seven climates with zonal theory by introducing seven 'climate regions', delimited now not by parallels but isotherms, which would become more and more 'undulated' and complex in nature with the inclusion of a rapidly growing number of global observations throughout the nineteenth century.

Faithful to the tradition of Humboldt's early map, Woodbridge's isothermal chart convinces with a simplistic design, reducing visual information to seven climate regions (delimited by isothermal lines and differentiated in function of colour), the geographical limits of agricultural production in function of temperature and the continental outlines, including only a strict minimum of topographical features. Traditional topographic information one would usually expect in particular in a school atlas was deliberately left out in order to direct the reader's attention to the essential information Woodbridge wished to convey. His chart also picks up a similar colour coding as already encountered in the medieval zonal maps discussed above, with strong red colour reserved to the 'torrid region', light green to the 'temperate' regions and blue tones to the 'wintery' and 'frozen' ones. These 


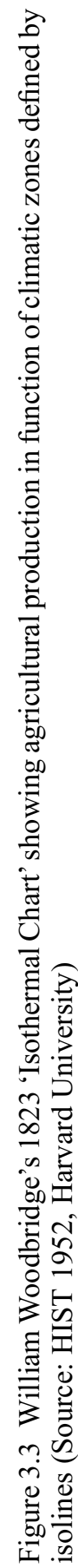


elements make Woodbridge's map an early forerunner of modern climate classification systems, although his work is mostly ignored by general classification histories. ${ }^{6}$ Finally, Woodbridge also believed in the superiority of visual media in geographical education, stating 'it is only by this process of [visual] comparison, that the great objects of geography - the expansion of the mind, and the discipline of the reflective powers - can be attained' (cited in Delaney 2012:62). This visual comparison of climate and agricultural production was made possible with two major achievements, a new climate definition, which was since Humboldt completely disconnected from the parallels, and the introduction of maps as analytical tools, allowing the spatialisation of all sorts of information for comparative and global analysis. Climate and its changes were central to this new visual, comparative approach, because it allowed the tackling of many pressing questions.

In particular, the link with agricultural production, spatially theorised in plant geography, had far reaching cultural, economic, scientific and political implications throughout the nineteenth century, of which only very few can be mentioned here (Schulten 2010). For instance, agricultural production was central to colonial discourse from mid-eighteenth century onwards in the French and British contexts, where it had become increasingly clear that insular climates were highly dependent on forestry questions and precipitation regimes (Grove 1995). In Algeria, in the eyes of the French colonists, it was their duty to rehabilitate and amend deleterious climate by, for example, planting eucalyptus trees in large numbers and introducing massive irrigation infrastructures. Back in Europe, regional climate changes were also noted, for instance in 1832 by Austrian astronomer and director of the Vienna observatory Joseph Johann Littrow, who thought it is very likely that climate in Middle and Northern Europe must have changed (it was probably rising according to him) due to the important draining of marshes and massive deforestation. General climate change, as discussed by many at the time, in particular, after large parts of Europe experienced severe weather events (resulting from the 1815 eruption of Tambora in Indonesia), should however, according to Littrow, not be inferred from temperature records (Littrow 1832). The observation of general climate change tendencies was in other words a highly controversial topic, and whereas some authors claimed to have proof for historical climate changes, Danish geographer and botanist Schouw noted, for instance, only a few years before Littrow that there were no indications for a changing climate in any of the meteorological and other records one could find in Denmark and Scandinavia (Schouw 1827).

\footnotetext{
${ }^{6}$ No mention, for instance, in the Glossary for Meteorology of the American Meteorological Society: http:// glossary.ametsoc.org/wiki/Climatic_classification (accessed 5 December 2017) nor in the classic textbooks, such as Owen Box (2016).
} 
Visualising Climate and Climate Change

\subsection{Historical Trajectories towards Contemporary Climate Change Icons}

The link established between plant distribution, temperature and its underlying laws was absolutely crucial for the debates that followed because it had important repercussions on climate change theory as it resurfaced during the Cold War, thus shaping at least in part many of the famous climate change icons we know today. For instance, the field of historical climatology was born precisely out of this new interconnected field of investigation, infused by the widely circulated climate visualisations of Humboldt and Schouw, and thereafter picked up, during the second half of the nineteenth century, in many influential thematic maps produced by Woodbridge, Berghaus, Petermann, Johnston, Cartee, Bromme, Guyot and others. Although Woodbridge's visual simplicity would not persist as a dominant visualisation mode (indeed, more and more information was included in maps especially from the 1850s onwards), the visual style of Woodbridge's maps dominated weather and climate visualisations in atlases well into the 1870s. More importantly, these maps spawned research on historical vegetation data-pushed in France by astronomer François Arago, based for instance on the dates of grape harvest or the geographical distribution of date palms - in order to allow the reconstruction of climates of the past few thousand years (Arago 1858, see also Locher and Fressoz 2012).

Although not directly related to our visual climate history, one must nonetheless mention here that the timescales of historical climatology were even further expanded by the rise of the theory of ice ages during the second half of the nineteenth century, born once again out of fears of a changing climate. It dominated the climate research agenda for almost 100 years until the rapid expansion of the Earth sciences at the beginning of the Cold War and the subsequent introduction of numerical modelling in climatology. ${ }^{7}$ The existence of ice ages in former times required addressing timescales that were much vaster than any timescales considered beforehand, demanding also novel explanations for large changes in mean temperature. Thus, especially two research fields had a lasting impact on the following climate change debate: the modification of the Earth's orbital configuration and the chemical composition of the atmosphere, the latter including of course the carbon dioxide-induced greenhouse effect. Yet contrary to common historical belief, many of the so-called precursors, generally identified as the initiators of the theory of climate change (John Tyndall, Svante Arrhenius or Thomas Chamberlin),

\footnotetext{
${ }^{7}$ Born out of the Swiss context of glacier research and fears of a gradual cooling in Europe, Swiss engineer Ignace Venetz proposed in 1821 (published in 1833) that in the dim past, enormous glaciers covered the alpine regions (Venetz 1833).
} 
were not so much worried about human-induced climate change but were rather seeking to explain the ice ages (Brönnimann 2002, Locher and Fressoz 2012).

Finally, and this is crucial for our longue durée visual perspective, visualisations of geographical plant distribution (in function of mean temperature and precipitation) gave rise to the most influential climate classification still in use today: the KöppenGeiger climate classification. Picking up on Humboldt's and Woodbridge's important work, and further popularised by Berghaus, Dove, Supan, Grisebach and others, the Russian-German meteorologist Wladimir Köppen first proposed in 1884 a draft of a new climate classification system, transformed in 1900 into a mathematical system of climate classification, dividing the world into various climate types, a system he would subsequently refine throughout his career until his death in 1940 (Köppen 1884). His three-letter system consisted in classifying climate according to five climate categories (first level of description: tropical, dry, temperate, boreal and polar climate, labelled A to E, derived maybe from Swiss-French botanist De Candolle's vegetation groups), taking further into account seasonal variations in precipitation (second level of description) and monthly mean temperature (third level). The system's main aim was to represent areas with similar climatic conditions whose statistical properties would yield similar vegetation types, thus revealing the geographical complexity of climates at a regional level. After Köppen's death, German climatologist Rudolf Geiger - with whom Köppen collaborated to author the multiple-volume work Handbuch der Klimatologie (Handbook of Climatology) - published in 1961 the last version of his climate classification as a large wall map for use in teaching (Geiger 1961). Today, it remains the most popular and most influential climate classification, with applications in a broad diversity of fields (Rubel and Kottek 2011).

And since modern climatology is more concerned with prediction than description (see on prediction the first chapter in this volume), the Köppen climate classification did not just remain a useful resource for teaching, but it also became an important tool of climate change research. For instance, the Köppen classification was used in 1975 by pioneers of numerical climate modelling Manabe and Holloway as one of the first benchmarks to verify the output of global climate models (Manabe and Holloway 1975). Many other influential applications followed (as, for instance, its use in model intercomparison) so that today the Köppen classification is considered 'a standard part of future efforts to develop and evaluate AOGCMs' (atmosphere-ocean general circulation models) (Rubel and Kottek 2011:363, see also Jylhä et al. 2010). Indeed, since the publication of digital world maps for an extended period (covering now 1901 to 2100), the visualisation of global trends and projected shifts of climate zones according to different IPCC scenarios has become an influential tool for climate change research. Thus, since the 1970s, climate classifications and their visualisations are once again firmly 
embedded in climate change discussions, with the naturalistic, quantitative approach now clearly established as the dominant way to describe climate and its changes.

Two types of visualisations illustrate this historical development very clearly. The first are global maps and computer animations produced by an interdisciplinary team of climate researchers, showing on world maps for the twenty-first century shifting Köppen climate zones in function of different IPCC greenhouse gas scenarios, with expected shifts of certain climate classes for some scenarios estimated by the end of the century at almost 5 per cent (see Figure 3.4) (Rubel and Kottek 2010). ${ }^{8}$ Although isolines are now absent from these maps because of a more regional approach to climate classes and the inclusion of precipitation data, there is still a striking resemblance with Woodbridge's isothermal chart from 1823, in particular the colour coding which remains almost the same.

In a very similar way, but on a more regional scale, scientists from the Finish Meteorological Institute produced maps showing shifting Köppen climates on the scale of Europe. Backed by a questionnaire, their study provides some evidence that maps can be an effective way of visualising and disseminating information concerning regional climate change, especially to non-experts, policy makers and the general public (Jylhä et al. 2010).

A second, closely related type of visualisation is that of 'spatial analogues' which consists mostly in looking 'for regions where the present-day climate resembles the anticipated future climate of the study area' (Jylhä et al. 2010:162). Used since the 1980s in particular to inform agricultural studies on climate change (Parry 1988), climate analogue studies have remained, especially with the rise of numerical modelling since the 1990s, an influential approach, despite numerous drawbacks such as 'distorting the geographical configurations between locations' (Jylhä et al. 2010:162, see also Hallegatte et al. 2007). Today, with the help of web tools such as the Climate Analogues online platform, anybody with an Internet access can search for and explore possible climate analogues for almost any place on Earth. ${ }^{9}$

\subsection{Conclusion: Moving towards Mobile Climates}

The two last examples show very well that global climate change now confronts us with mobile climates where fixed categories no longer exist. Climates within the contemporary climate change regime, and this is a key insight of our longue durée visual perspective, have in other words become migrant - along with crops,

\footnotetext{
8 Animated maps can be accessed here: http://koeppen-geiger.vu-wien.ac.at/ (Accessed 5 December 2017).

9 See: www.ccafs-analogues.org/tool/ (accessed 5 December 2017).
} 


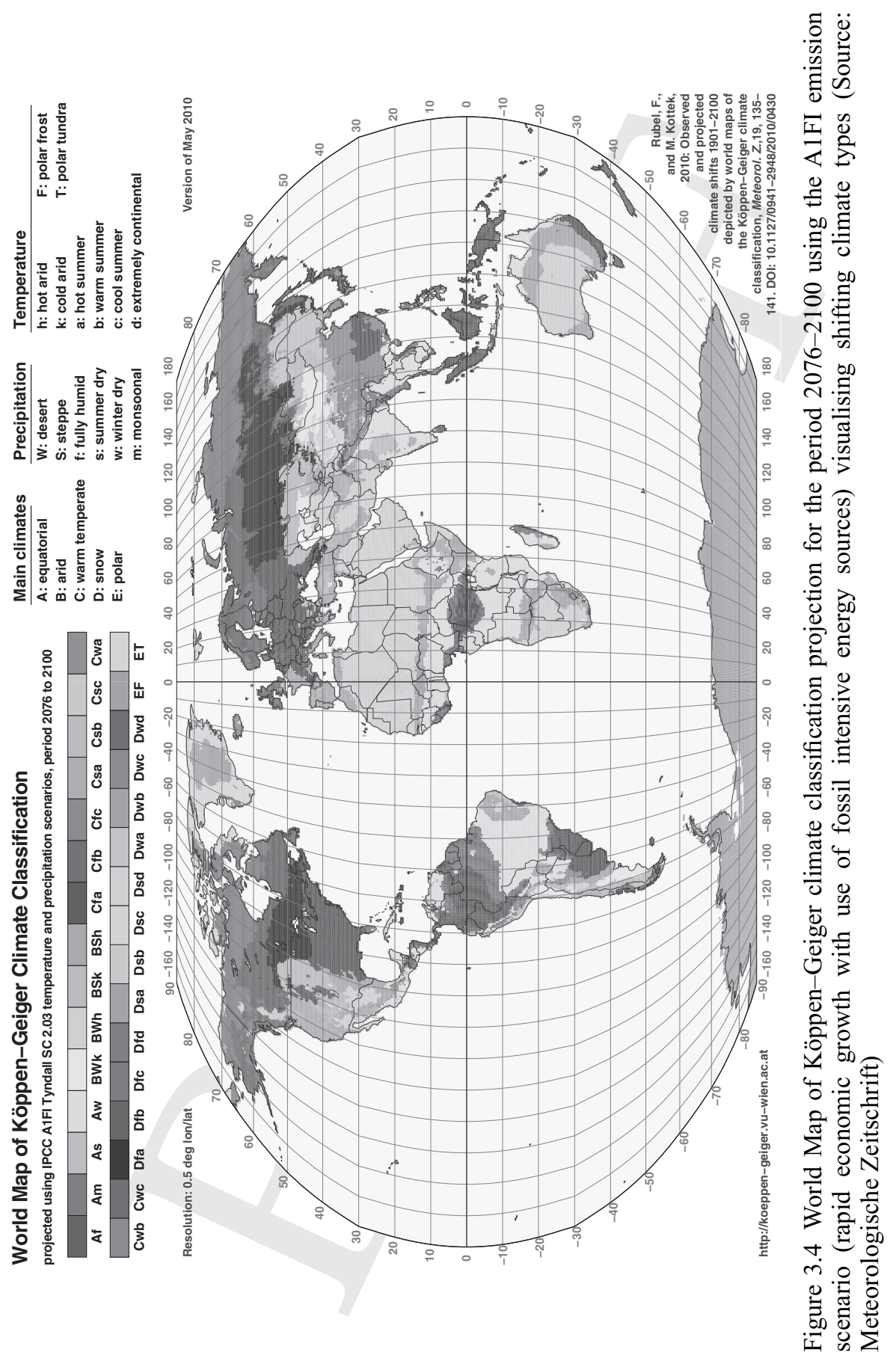


animals, diseases and people. It is no longer the colonial administrator who confronts himself to the dangers of the so-called torrid zone, or the explorer who ventures into the forbidding climes of the polar regions, equipped each time with ideas of stable climates and distinct zones, each attached to specific views on nature and society. Today, the situation is somewhat inversed, with the 'tropics' inviting themselves to 'us', as evidenced, for instance, in climate change exhibitions such as Postcards from the Future (London 2010) or in the recurrent use of the motif of glaciers and palm trees in the Swiss publishing context (Brönnimann 2002; Mahony 2016). Both examples reveal that mapping is only one of many visual strategies deployed, with montage being another key visual strategy used to visualise the mobility of climates.

There are, however, also important limits to these approaches. Indeed, as Mahony has convincingly argued, the fear of tropical invasion, as promoted in Postcards from the Future, comes with a highly typified view of the tropics 'neglecting a fuller politics of human mobility, urbanisation and the global interconnections through which human populations are jointly engaged in the ongoing composition of a common, climate-changed world' (Mahony 2016).

Yet, despite these limitations to which scholars must remain of course attentive, visually exploring the mobility of climates can provide nonetheless a means for conveying (at least to some degree) the highly dynamic nature of climate change, especially when addressing the lay public. The above-mentioned climate analogue studies may be helpful here in particular when it comes to communicating the observed rapidity of changing climates. In the past, most geographical climate analogue studies explored analogies between current and future climates, but it is also possible to take a look at the past. For instance, in a recent study, Beniston proposed 'to assess the manner in which climatic conditions in European cities in the last decade compare with those that prevailed in the 1950s in other locations generally located well to the south' (Beniston 2014:1839). The advantage of this study and of the resulting maps is that they give an idea of how rapidly our climates are changing, with isotherms moving in some cases between geographical locations as fast as 14 kilometres per year in a northward direction. This means that some places are now experiencing temperatures that were recorded already over half a century ago at places located up to 500 kilometres to the south.

To be sure, as a purely statistical approach this type of analogue study comes once again with major drawbacks, mainly because local geographic conditions are voluntarily neglected and temperature and precipitation remain the sole important variables considered. However, as a historical approach, it opens an important field of investigation which can prove fruitful in the future. Indeed, the historical perspective - just as attempted by this longue durée visual perspective on climate and its changes - invites us to think more deeply about climatic difference and to 
trace the changing values and functions attached to climates, the geographical imaginations and moral assumptions mobilised when referring to them, as well as the cultural associations that go with them. As we have seen, the visual perspective can be crucial here, revealing largely ignored geographical traditions, showing also that the dominant geophysical approach grew gradually out of far broader investigations into climate and its changes and finally that moral assumptions were often closely attached to climate classifications and that these considerations are not likely to go away in current heated debates on the refugee crisis and the idea that the 'tropics' are inviting themselves to 'us'.

Moreover, and this is a second, closely connected key insight, the longue durée visual perspective reveals that throughout history, climate visualisations were accompanied by a fundamental aesthetic and educational desire making the eye the primary organ for knowledge construction and pedagogical reasoning. As we have seen above, this tradition reaches from Macrobius to Woodbridge and Humboldt and stretches even to the most recent climate classifications and their projections. This begs of course the important question about the role that the visual can and should play in the construction and communication of climate knowledge and its imaginings.

The pessimistic observer may claim that after all, climate science has already brought about some of the most robust scientific climate change icons we are all familiar with today, such as the Keeling curve, showing ever-rising carbon dioxide levels since the International Geophysical Year (1957-58). Yet even the Keeling curve - made up of its two powerful storylines of a 'breathing Earth' and an atmosphere that is becoming less and less respirable - failed to induce long-term political action, just as most of the other famous climate change icons failed too (Howe 2015).

There is of course no simple answer to this dilemma, nor is there a single explanation that could account for the past failures (but see Grevsmühl 2017). However, as I have argued elsewhere, some of these issues are at least partly due to the fact that most global environmental icons struggle to become meaningful in everyday living (Grevsmühl 2016). They remain 'psychologically sterile' because they promote a very specific worldview that is clearly not shared by everyone, or to put it in other words: the 'view from everywhere' (Hulme 2010) rarely coincides with the 'view from everyone'. One major bias is that there are privileged sites for detecting global environmental change and not all individuals, institutions or states have the same access to the tools and infrastructures that allow to create global environmental knowledge, nor do they consume this knowledge in the same way. In particular in hindsight of recent political developments and a general crisis of trust, accompanied by calls for more democratic participation processes, the pessimistic observer may therefore conclude that the importance of the visual is 
overstated and that one urgently should look for other alternatives based on more inclusive knowledge-construction processes.

Yet recent developments show that this pessimism is perhaps unfounded. Indeed, many of the recent initiatives within climate change research are well aware of at least some of the above-mentioned shortcomings. As a potential first step in the right direction, the Finnish example discussed above of shifting Köppen climates mapped at a European level shows that the visual can contribute to making climate change meaningful for local populations by taking into account at least to some degree local geography - which is of course all about the complex, local interactions between societies and nature. Bringing climate change so to speak 'back to the ground', with the help of, for instance, more regional or local mapping approaches, is therefore probably one of the greatest challenges but also one of the most promising contributions the visual domain will offer in the immediate future. Yet the full potential of the visual will most certainly only be attained by including a historical perspective that invites challenges to general cultural assumptions associated with changing climates. Thus, the predictive tools of scientific and political analysis will only become truly meaningful if equipped with fundamental reflections on how the past confronted the climate question.

After all, in light of recent discussions concerning the notion of the Anthropocene, of the need to connect both the natural history of humans as a species and their cultural history as a more differentiated historical, economic and thus political account of humanity (Chakrabarty 2009), climate is, as observed above through the eye of the visual, a unique opportunity to rethink from a longue durée perspective the relationship not only of humankind and nature but also of culture and climate.

\section{Acknowledgements}

The author would like to thank his colleagues of the environmental history research group at EHESS (GRHEN) for thoughtful critics, comments and ideas as well as the editors for their valuable support, guidance and suggestions.

\section{References}

Altmann, A. and Schramm, L. 2005. Judah Halevi's theory of climates. Historical Studies in Science and Judaism, 5, 215-46.

Arago, F. 1858. Sur l'état thermométrique du globe terrestre. Cuvres complètes, tome 8, Paris: Gide, 184-646.

Beniston, M. 2014. European isotherms move northwards by up to $15 \mathrm{~km}$ year $^{-1}$ : Using climate analogues for awareness-raising. International Journal of Climatology, 34, 1838-44. 
Berlinghieri, F. 1480. Geographia, Firenze: Nicolo Todescho.

Owen Box, E. 2016. Vegetation Structure and Function at Multiple Spatial, Temporal and Conceptual Scales, New York: Springer.

Brönnimann, S. 2002. Picturing climate change. Climate Research, 22, 87-95.

Cellarius, C. 1731. Veteris Orbis Climate ex Strabone, map 1:50 million, Leipzig.

Chakrabarty, D. 2009. The climate of history: Four theses. Critical Inquiry, 35(2), 197-222.

Corneille, T. 1708. Dictionnaire universel, géographique et historique, tome 1, Paris.

Cosgrove, D. 2007. Mapping the world. In Akerman, J., and Karrow Jr., R. (eds.), Maps: Finding Our Place in the World, Chicago: University of Chicago Press, 65-116.

Delaney, J. 2012. First X, Then Y, Now Z: An Introduction to Landmark Thematic Maps, Princeton: Princeton University Library.

Diderot and d'Alembert. 1753. Encyclopédie ou dictionnaire raisonné des sciences, des arts et des métiers, vol.3, Paris.

Fleming, J. 1998. Historical Perspectives on Climate Change. Oxford: Oxford University Press.

Fleming, J. and Jankovic, V. 2011. Revisiting Klima. Osiris, 26(1), 1-15.

Fries, L. 1541. Typus Orbis Descriptione Ptolemaei, Vienna: Gaspard Trechsel.

Geiger, R. 1961. Köppen-Geiger, Klima der Erde, map 1:16 million, Gotha: Klett-Perthes.

Golinski, J. 2007. British Weather and the Climate of Enlightenment, Chicago: University of Chicago Press.

Grevsmühl, S. V. 2017. A visual history of the ozone hole: A journey to the heart of science, technology and the global environment. History and Technology, 33(3), 333-44.

Grevsmühl, S. V. 2016. Images, imagination and the global environment: Towards an interdisciplinary research agenda on global environmental images. Geo: Geography and Environment, 3(2), e00020.

Grevsmühl, S. V. 2014. The creation of global imaginaries: The Antarctic ozone hole and the isoline tradition in the atmospheric sciences. In: Schneider, B., and Nocke, T. (eds.), Image Politics of Climate Change. Bielefeld: Transcript Verlag, 29-53.

Grove, R. 1995. Green Imperialism: Colonial Expansion, Tropical Islands, Edens, and the Origins of Environmentalism, 1600-1860, Cambridge: Cambridge University Press.

Hallegatte, S., Hourcade, J.-C., and Ambrosi, P. 2007. Using climate analogues for assessing climate change economic impacts in urban areas. Climatic Change, 82, 47-60.

Halley, E. 1686. An historical account of the trade winds .... Philosophical Transactions of the Royal Society of London, 16, 153-68.

Heymann, M. 2010. The evolution of climate ideas and knowledge. WIREs Climate Change, 1(4), 581-97.

Hiatt, A. 2007. The map of Macrobius before 1100. Imago Mundi, 59(2), 149-76.

Honigmann, E. 1929. Die sieben Klimata, Heidelberg: Carl Winter's Universitätsbuchhandlung.

Howe, J. 2015. This is nature, this is un-nature: Reading the keeling curve. Environmental History, 20(2), 286-93.

Hulme, M. 2015. Climate and its changes: A cultural appraisal. Geo: Geography and Environment, 2(1), 1-11.

Hulme, M. 2010. Problems with making and governing global kinds of knowledge. Global Environmental Change, 20(4), 558-64.

von Humboldt, A. 1813. 'Des lignes isothermes et de la distribution de la chaleur sur le globe', Mémoires de physique et de chimie de la Société d'Arcueil, vol.3.

IPCC 2001. Climate Change 2001: The Scientific Basis. Contribution of Working Group I to the Third Assessment Report of the Intergovernmental Panel on Climate Change, Cambridge: Cambridge University Press. 
Jankovic, V. 2000. Reading the Skies: A Cultural History of English Weather, Manchester: Manchester University Press.

Jylhä, K., Tuomenvirta, H., Ruosteenoja, K., Niemi-Hugaerts, H., Keisu, K., and Karhu, J. A. 2010. Observed and projected future shifts of climatic zones in Europe and their use to visualize climate change information. Weather, Climate and Society, 2, $148-67$.

Köppen, W. 1984. Die Wärmezonen der Erde. Meteorologische Zeitschrift, 1, 215-226.

Littrow, J. J. 1832. Über den gefürchteten Kometen des gegenwärtigen Jahres 1832 und über Kometen überhaupt, Wien: Carl Gerold.

Livingstone, D. N. 2002. Race, space and moral climatology: Notes toward a genealogy. Journal of Historical Geography, 28(2), 159-80.

Locher, F. 2008. Le savant et la tempête: Etudier l'atmosphère et prévoir le temps au XIXe siècle, Rennes: Presses Universitaires de Rennes.

Locher F. and Fressoz, J.-B. 2012. Modernity's frail climate: A climate history of environmental reflexivity. Critical Inquiry, 38(3), 579-98.

Mahony, M. 2016. Picturing the future-conditional: Montage and the global geographies of climate change. GEO: Geography and Environment, 3(2), e00019.

Manabe S. and Holloway, J. L. 1975. The seasonal variation of the hydrologic cycle as simulated by a global model of the atmosphere. Journal of Geophysical Research, 80, $1617-49$.

Martin, C. 2006. Experience of the new world and Aristotelian revisions of the earth's climates during the renaissance. History of Meteorology, 3, 1-15.

Mauelshagen, F. 2016. Ein neues Klima im 18. Jahrhundert. Zeitschrift für Klimatologie, 1, 39-57.

Maury's, M. F. 1907. New Elements of Geography, New York: American Book Company.

Regnauld, H. 2016. Coastal landscape as part of a global ocean: Two shifts. Geo: Geography and Environment, 3(2), e00019.

Rheinberger, H.-J. 2001. Objekt und Repräsentation. In: Heinz, B., and Huber, J. (eds.), Mit dem Auge denken, Zürich: Edition Voldemeer, 55-61.

Rubel, F. and Kottek, M. 2011. Comments on: 'The thermal zones of the Earth' by Wladimir Köppen (1884). Meteorologische Zeitschrift, 20(3), 361-5.

Rubel, F. and Kottek, M. 2010. Observed and projected climate shifts 1901-2100 depicted by world maps of the Köppen-Geiger climate classification. Meteorologische Zeitschrift, 19(2), 135-41.

Ruscelli, G. 1561. Ptolemaei Typus, Venice.

Sanson, N. and Sanson, G. 1697. Cartes et tables de la géographie ancienne et nouvelle, Paris.

Schneider, B. 2016. Der 'Totaleindruck einer Gegend': Alexander von Humboldts synoptische Visualisierungen des Klimas. In: Ette, O. and Drews, J. (eds.), Horizonte der Humboldt-Forschung, Hildesheim: Georg Olms Verlag, 53-78.

Schouw, J. F. 1827. Über die vermeintliche Veränderung der klimatischen Verhältnisse Dänemarks und der benachbarten Länder und über die Periodicität dieser Verhältnisse. Hertha, Zeitschrift für Erd-, Völker-, und Staatenkunde, 10, 307-53.

Schulten, S. 2010. Mapping the Nation: History and Cartography in Nineteenth-Century America, Chicago: University of Chicago Press.

Venetz, I. 1833. Mémoire sur les variations de la température dans les Alpes de la Suisse. Mémoires de la Société Helvétique des Sciences Naturelles, 1(2), 1-38.

Ward, R. 1908. Climate, Considered Especially in Relation to Man, London: John Murray.

Ward, R. 1905. The climatic zones and their subdivisions. Bulletin of the American Geographical Society, 37(7), 385-96.

Wilford, J. N. 1981. The Mapmakers, New York: Knopf. 